\title{
Pancreatic alkaline phosphatase and a tumour variant
}

\author{
T. W. WARNES, W. R. TIMPERLEY, PAULINE HINE, AND G. KAY \\ From the Departments of Gastroenterology and Pathology, Manchester Royal Infirmary, Manchester
}

SUMMARY Alkaline phosphatase has been extracted from human pancreas with n-butanol and has been shown to have distinctive isoenzyme characteristics when compared with the enzymes of small intestine and of normal serum. The enzyme has been demonstrated histochemically in a carcinoma of the pancreas and also in an islet cell tumour and the tumour enzyme has been shown to be unique, not only electrophoretically, but in being remarkably heat sensitive and in being activated by low molarities of urea.

Alkaline phosphatase has recently been reported in the duct system, islet cells, and acini of the human pancreas (Warnes and Bulmer, 1970). The enzyme is known to exist in multiple molecular forms, termed isoenzymes, which differ in biochemical characteristics in such a way that the different organ sources of alkaline phosphatase in serum can be detected by means of differing rates of heat inactivation (Posen, Neale, and Clubb, 1965) and urea inactivation (Bahr and Wilkinson, 1967) and differing reactions with L-phenylalanine (Fishman, Green, and Inglis, 1963), together with electrophoretic separation on a variety of media (Newton, 1967; Kaplan and Rogers, 1969). Studies with neuraminidase have shown that alkaline phosphatase isoenzymes may differ in their content of neuraminic acid (Robinson and Pierce, 1964) and that in some tissues this may be one of the bases of their heterogeneity (Butterworth and Moss, 1966; Bachawat, 1969).

The sources of alkaline phosphatase in human serum include liver, bone, small intestine, and placenta, but recently a wide variety of tumours have been shown to secrete alkaline phosphatase into the blood (Lancet, 1969). This tumour alkaline phosphatase, termed the 'Regan isoenzyme', is recognizable biochemically since it has properties identical to those of placental alkaline phosphatase both electrophoretically, and in being heat stable and highly sensitive to L-phenylalanine (Fishman, Inglis, Stolbach, and Krant, 1968; Stolbach, Krant, and Fishman, 1969). In this paper the isoenzyme characteristics of normal pancreatic alkaline phosphatase are described and contrasted with the alkaline phos-

Received for publication 19 April 1972. phatase extracted from two pancreatic tumours which has unique properties differing markedly from those of the Regan isoenzyme. Neuraminidase studies show that the difference between normal pancreatic alkaline phosphatase and the tumour isoenzyme is not explained by their differing contents of sialic acid.

\section{Materials and Methods}

Fresh pancreas was obtained at operation from patients undergoing total or partial pancreatectomy for chronic pancreatitis or during the course of gastrectomy for gastric carcinoma. From this material portions were obtained which were both macroscopically and microscopically normal. Tissue extracts of this material, together with a carcinoma of the body of the pancreas obtained at laparotomy, and an insulinoma obtained at necropsy, were made by extraction with n-butanol (Morton, 1954). Cryostat sections were cut from normal pancreas and the two tumours and stained for alkaline phosphatase by the method of Burstone (Burstone, 1958a and b). Alkaline phosphatase determinations on the tissue extracts were by the Kind-King modification of the King-Armstrong method (Kind and King, 1954).

HEAT INACTIVATION

Studies were based on the method of Posen et al (Posen, Neale, and Clubb, 1965).

UREA INHIBITION

Tests were performed by a modification of the method of Bahr and Wilkinson (1967). 


\section{PHENYLALANINE INHIBITION}

This was performed by comparing the enzyme activity of the test solution when $5 \mathrm{mM}$ L-phenylalanine was present in the assay system, with the activity of the same extracts in the presence of D-phenylalanine (Fishman et al, 1963).

\section{ACR YLAMIDE GEL ELECTROPHORESIS}

Samples of the extracts were subjected to 'disc' electrophoresis in a Shandon electrophoresis tank (Shandon Scientific Company Ltd, London), using a $5 \%$ polyacrylamide gel and a continuous buffer system (Smith, Lightstone, and Perry, 1968). A sample of normal serum was run in parallel for comparison. The enzyme bands were located by staining with $\beta$-naphthyl phosphate and Fast Blue BB.

\section{PREINCUBATION WITH NEURAMINIDASE}

Before electrophoresis this was carried out by the method of Robinson and Pierce (1964). Aliquots, each of $0.05 \mathrm{ml}$, of Vibrio cholerae neuraminidase

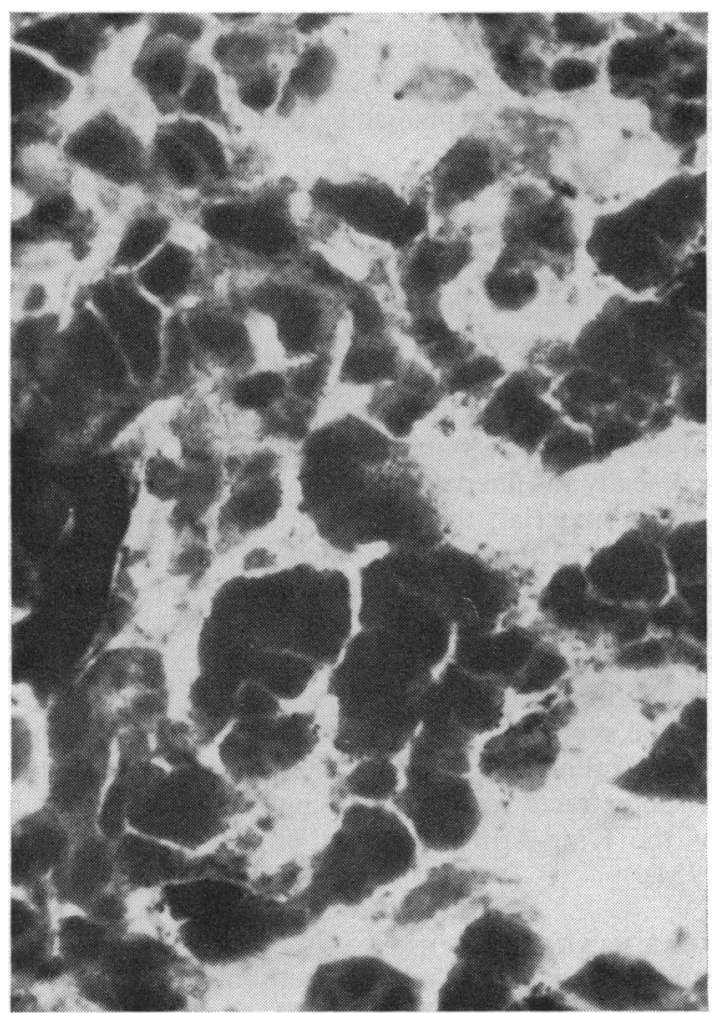

Fig. 1
(Koch-Light) containing 500 units $/ \mathrm{ml}$ were incubated with $0.05 \mathrm{ml}$ of tissue extract at $37^{\circ} \mathrm{C}$ for 20 hours before acrylamide gel electrophoresis.

\section{Results}

\section{HISTOCHEMISTRY}

The cells of the poorly differentiated adenocarcinoma of the pancreas stained strongly for alkaline phosphatase (Fig. 1), which was also seen in reactive fibroblasts and capillaries in the tumour. The islet cell tumour showed a weaker reaction (Fig. 2).

\section{ISOENZYME STUDIES ON NORMAL PANCREAS}

There was quite a wide variation in the amount of alkaline phosphatase extracted from the six specimens of 'normal' pancreas, varying from 0.012 to $0.042 \mathrm{KA}$ units/mg protein; biochemically, however, pancreatic phosphatase behaved in a reasonably homogeneous manner. The pancreatic isoenzyme was very much more heat sensitive than the small intestinal enzyme (Fig. 3). The alkaline phos-

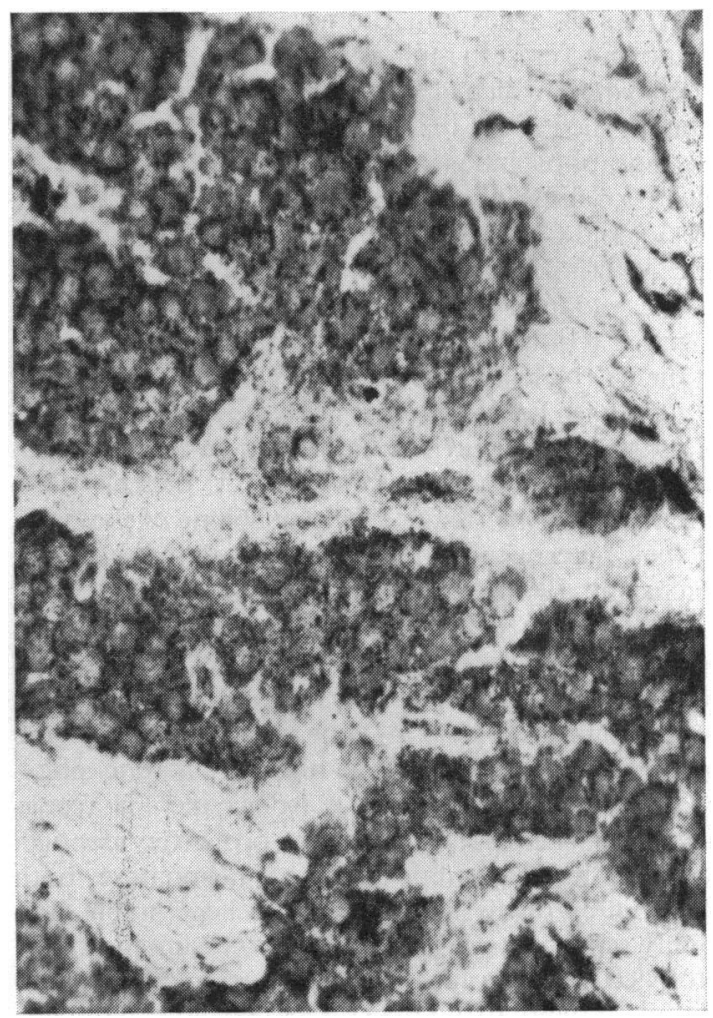

Fig. 2

Fig. 1 Alkaline phosphatase stain on poorly differentiated adenocarcinoma of pancreas showing strongly staining tumour cells. $\times 600$.

Fig. 2 Alkaline phosphatase stain on islet-cell tumour showing moderate staining of tumour cells. $\times 600$. 


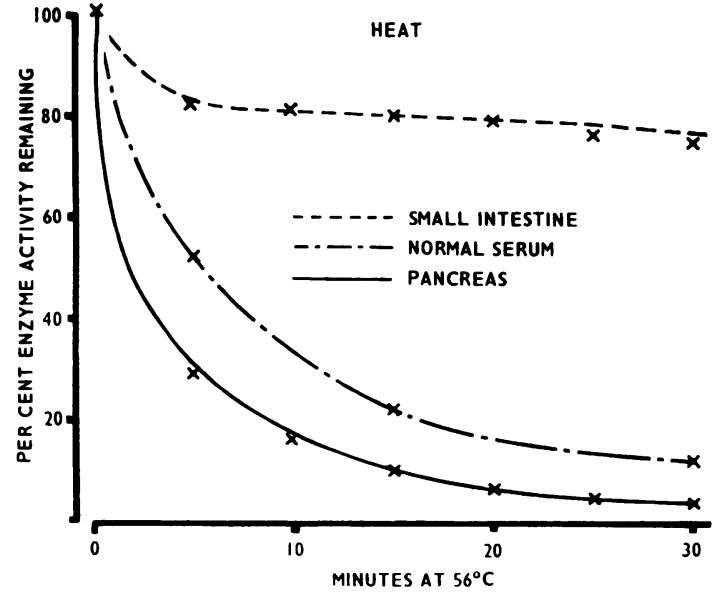

Fig. 3 Heat inactivation.

phatase of normal serum, which is included for comparison, was rather more heat stable than the pancreatic enzyme. The pancreatic enzyme was also more sensitive to urea inhibition than small intestinal alkaline phosphatase, the difference being most marked with 1 molar urea (Fig. 4). After incubation with the stereo-specific inhibitor L-phenylalanine, pancreatic alkaline phosphatase was largely unaffected, whereas the intestinal enzyme retained only $21 \%$ of its total activity.

Table I summarizes the percentage of alkaline phosphatase remaining after incubation with $5 \mathrm{mM}$ L-phenylalanine, after heating at $56^{\circ} \mathrm{C}$ for $15 \mathrm{~min}$, and after preincubation with 1 molar urea, each result being given with 1 standard deviation beneath. Thus pancreatic alkaline phosphatase is seen to be much more sensitive to heat and urea inactivation than is the small intestinal enzyme, but in contrast is largely unaffected by L-phenylalanine. For all three tests the differences between small intestinal and pancreatic alkaline phosphatase were statistically significant $(\mathrm{P}<0.004$ on the Mann-Whitney U test).

\begin{tabular}{lccc}
\hline & \multicolumn{3}{l}{ Percentage Alkaline Phosphatase after } \\
\cline { 2 - 4 } & $\begin{array}{l}\text { L Phenylalanine } \\
\text { Incubation } \\
(0.005 M)\end{array}$ & $\begin{array}{l}\text { Heat } \\
\text { at } 56^{\circ} \mathrm{C}\end{array}$ & $\begin{array}{l}\text { Urea } \\
\text { for } 15 \mathrm{Min} \\
(\text { IM) }\end{array}$ \\
\hline Small intestinal & 21.1 & 78.3 & 44.2 \\
(5) & \pm 6.0 & \pm 13.1 & \pm 7.7 \\
Pancreatic & $\mathbf{8 8 . 5}$ & 10.3 & 11.4 \\
(6) & \pm 10.8 & \pm 9.8 & \pm 12.0 \\
\hline
\end{tabular}

Table I Summary of inhibition studies

For all three tests P $<0.004$ (Mann-Whitney U test)

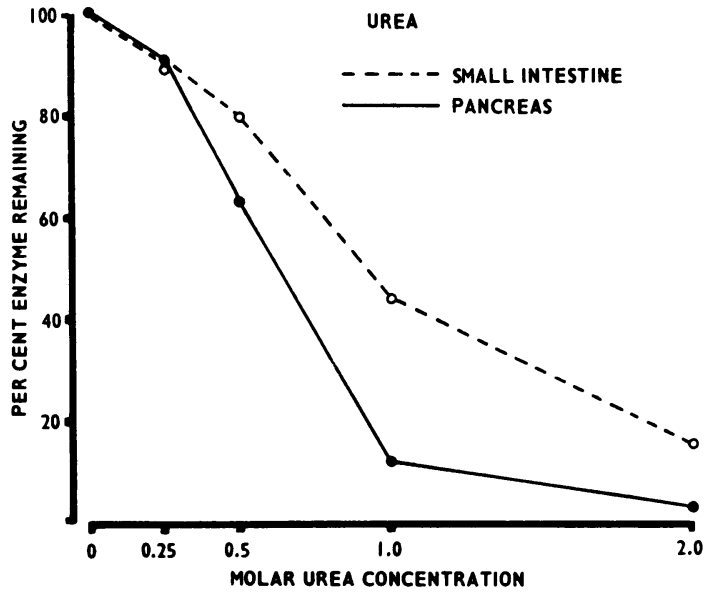

Fig. 4 Urea inhibition.

Electrophoretically, pancreatic alkaline phosphatase showed a diffuse band running behind the liver band in serum but slightly ahead of the more compact band of small intestine (Fig. 5). Liver and bone extracts are included in the photograph for comparison, together with serum from a patient with osteo-

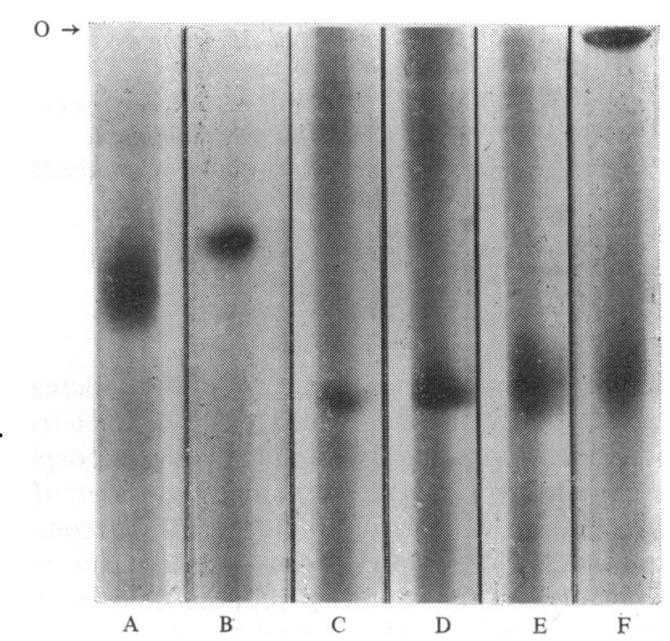

Fig. 5 Acrylamide gel disc electrophoresis. From left to right.

A Pancreatic extract

$B$ Intestinal extract

C Serum from a patient with liver disease

$D$ Liver extract

$E$ Serum from a patient with Paget's disease

$F$ Bone extract

(O marks the origin) 


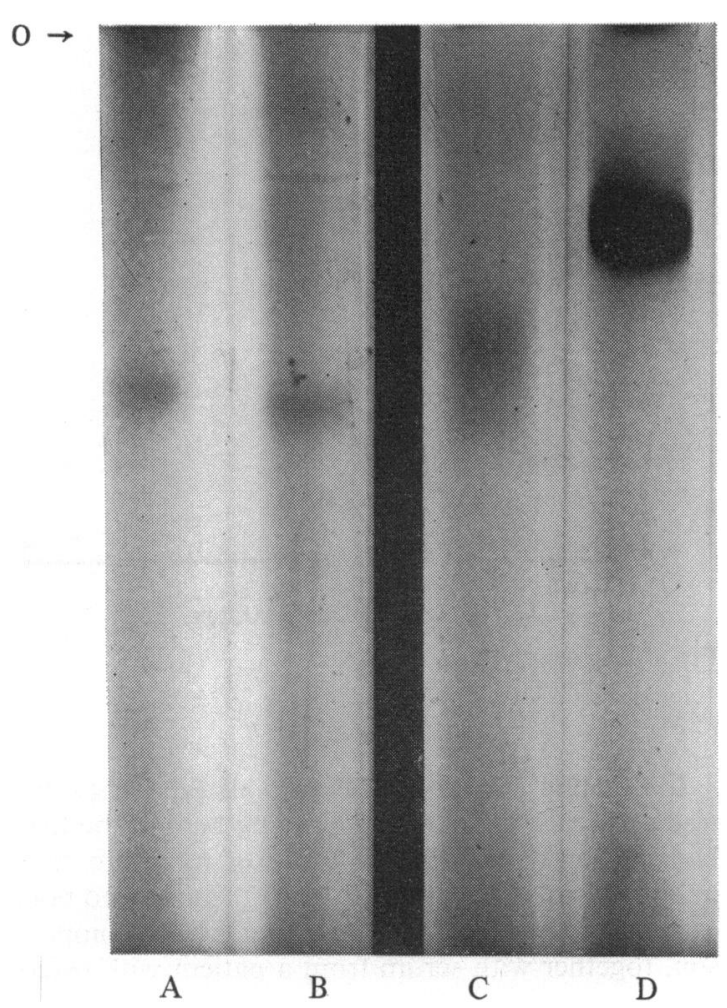

Fig. 6 The effect of neuraminidase on electrophoretic mobility.

Experiment $1\left\{\begin{array}{l}A \begin{array}{l}\text { Small-intestinal AP without } \\ \text { neuraminidase. }\end{array} \\ B \begin{array}{l}\text { Small-intestinal AP following pre- } \\ \text { incubation with neuraminidase. }\end{array} \\ \text { Experiment } 2\end{array}\left\{\begin{array}{l}C \text { Pancreatic AP without neuraminidase. } \\ D \text { Pancreatic AP following pre- } \\ \text { incubation with neuraminidase. }\end{array}\right.\right.$
(O marks the origin)

blastic bone disease, and it is clear that the pancreatic isoenzyme is electrophoretically quite distinct from bone, liver, and small intestinal alkaline phosphatases. A further important difference was seen after preincubation with neuraminidase; this removes neuraminic acid residues from phosphatases containing this substance and so reduces their electrophoretic mobility. The mobility of pancreatic alkaline phosphatase was reduced by neuraminidase, indicating that this isoenzyme contains neuraminic acid (Fig. 6, experiment 2); the mobility of small intestinal alkaline phosphatase is, in contrast, unaffected by neuraminidase (Fig. 6, experiment 1).

TUMOUR ISOENZYME STUDIES

The phosphatase of the two tumours differed from

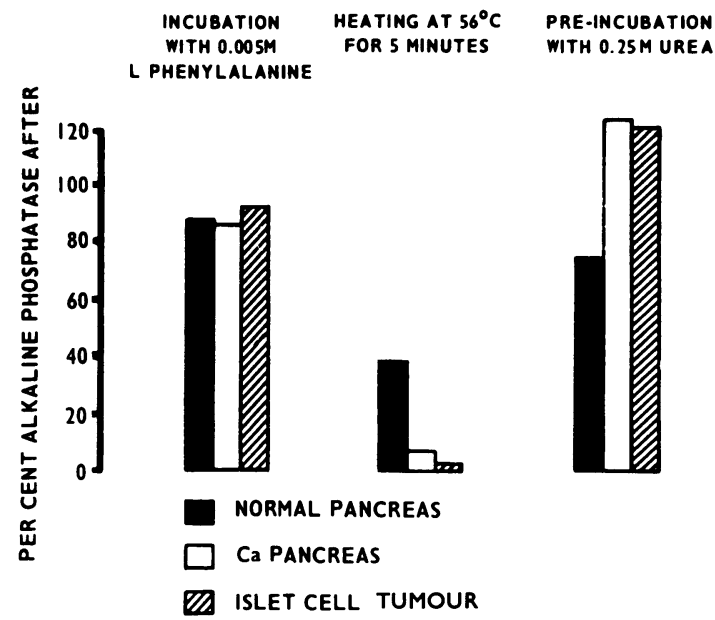

Fig. 7 Inhibition studies on the AP isoenzymes of normal pancreas and the tumour variant.

The biochemical characteristics of the two tumours are depicted in the two right-hand columns of each figure. Along the ordinate is again shown the percentage enzyme activity remaining after the respective inhibitions with phenylalanine, heat, and urea.

that of normal pancreas in being remarkably heat sensitive and in showing approximately $20 \%$ activation by 0.25 molar urea (Fig. 7). The percentage inhibition with L-phenylalanine was, however, the same in the two tumours as in normal pancreas.

These biochemical differences were associated with electrophoretic differences between the tumour isoenzymes and that of normal pancreas (Fig. 8). Both tumours showed a main band in an identical position to that of normal pancreas but the carcinoma of pancreas showed in addition two well defined, slow running minor bands, whilst in the islet cell tumour there was a minor band running immediately ahead of the main band. However, the electrophoretic mobility of the main bands was reduced by preincubation with neuraminidase in all three cases. It is likely, therefore, that the tumour isoenzyme represents the production of a modified polypeptide rather than a difference in neuraminic acid content.

\section{Discussion}

This work shows that pancreatic alkaline phosphatase is an isoenzyme which is quite distinct from small intestinal alkaline phosphatase in that it is virtually unaffected by $0.005 \mathrm{M}$ L-phenylalanine and is very much more heat and urea sensitive. 


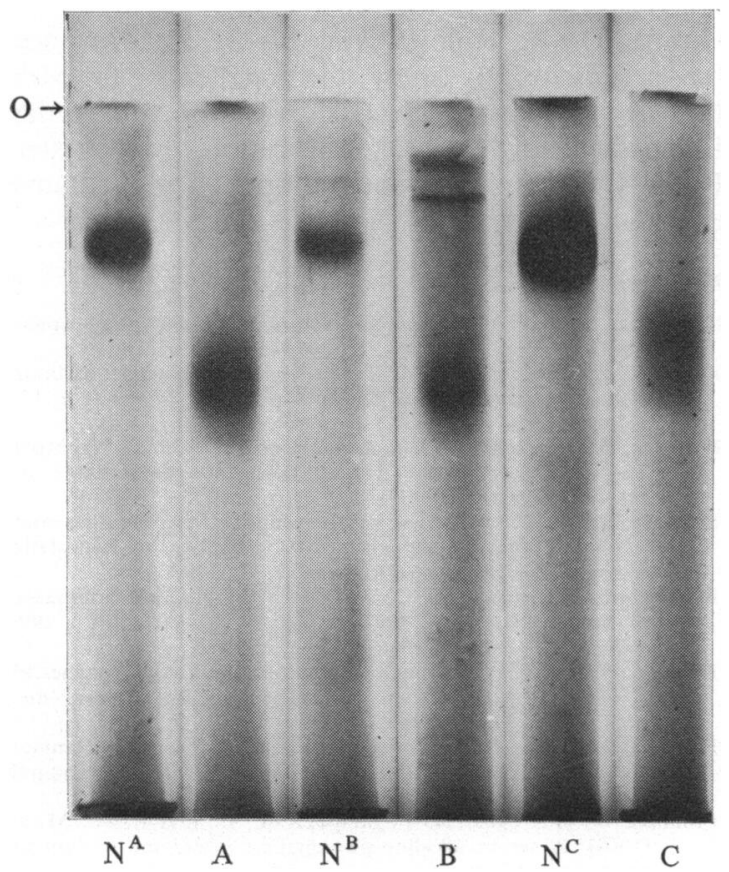

Fig. 8 The effect of neuraminidase on the tumours. $A$ Islet cell tumour

$B$ Carcinoma of pancreas

C Normal pancreas

The left hand gel of each pair, marked $N^{A}, N^{B}$, and $N^{C}$ respectively, represent $A, B$, and $C$ following preincubation with neuraminidase.

(O marks the origin)

Whilst pancreatic alkaline phosphatase is somewhat more heat and urea sensitive than serum alkaline phosphatase, there are wide variations in the inhibition characteristics of the latter, depending on the type of alkaline phosphatase predominating in that particular serum, and consequently the differences between pancreatic alkaline phosphatase and the enzyme of normal serum are not statistically significant. However, pancreatic alkaline phosphatase is clearly distinguishable electrophoretically from the enzyme found in normal serum. Molecular weight estimation on Sephadex G200 gave an approximate molecular weight of 100000 for pancreatic alkaline phosphatase compared with 140000 for the normal serum enzyme (T. W. Warnes and S. Smith, unpublished observations). There is a clear difference between pancreatic alkaline phosphatase and intestinal alkaline phosphatase when they are treated with neuraminidase, which slows pancreatic alkaline phosphatase but has no effect on the intestinal enzyme. It therefore appears that, like kidney alkaline phosphatase, but unlike intestinal alkaline phosphatase, pancreatic alkaline phosphatase is a neuraminic-acid containing glycoprotein.

Alkaline phosphatase has been reported in a variety of tumours, but not to our knowledge in a carcinoma of the pancreas or an islet cell tumour. There is clear evidence that tumours may secrete variant forms of alkaline phosphatase into the circulation. Thus, Gault, Cohen, Kahana, Leelin, Meakins, and Aronovitch (1967) described instances of lung cancer with raised serum alkaline phosphatase but no evidence of bone or liver metastases, and Nichols, Bower, Williams, and Martin (1966) reported an adrenal carcinoma with a raised level of alkaline phosphatase in serum, which fell after removal of the tumour. A variant form of alkaline phosphatase has been found in the serum of patients with rectal and gastric carcinomas which was identical electrophoretically to that extracted from tumour tissue (Klein, 1968) and tumour variant forms of the enzyme have been found in the serum and tumour tissue of patients with hepatocellular carcinoma (Warnock and Reisman, 1969) and carcinoma of the bronchus (Timperley, 1968). The importance of ectopic alkaline phosphatase production by tumours has been highlighted by the finding of Fishman et al of the Regan isoenzyme, which has been isolated from the serum and tumour tissue of patients with a wide variety of tumours including carcinoma of lung, ovary, colon, breast, uterus, and cervix, as well as reticulum cell sarcoma, Hodgkin's disease, and multiple myeloma (Stolbach et al, 1969). This tumour variant is indistinguishable from placental alkaline phosphatase either electrophoretically or in its marked heat stability and its sensitivity to L-phenylalanine, though more recently urea inactivation studies have shown a greater urea sensitivity of the Regan isoenzyme when compared with the placental isoenzyme, suggesting that their three-dimensional structure is different (Fishman, 1969). The tumour variant may be found in the serum of cancer patients who have quantitatively normal values of serum alkaline phosphatase (Stolbach, 1969). The tumour variant we have found in the pancreas is, however, clearly different from the Regan isoenzyme in that it is remarkably heat sensitive and resistant to $L$ phenylalanine; it is in fact the most heat-sensitive isoenzyme of alkaline phosphatase so far reported. The finding of a heat-sensitive, phenylalanineresistant tumour isoenzyme of alkaline phosphatase is in accord with the findings of similarly heat-labile and phenylalanine-resistant tumour isoenzymes isolated from other tissues (Timperley, 1968; Timperley and Warnes, 1970) but the activation of tumour alkaline phosphatase by low molarities 
of urea is, in our experience, unique, though other workers, using a similar technique, have found an activation of liver alkaline phosphatase by low concentrations of urea (Bahr and Wilkinson, 1967). It is therefore clear that tumours may produce alkaline phosphatase isoenzymes other than Regan isoenzyme. The latter has been postulated to arise as a result of genome derepression, possibly associated with the action of a virus within the tumour cells (Stolbach et al, 1969); the heat-sensitive tumour variant we describe is, in contrast, in accord with the observation that mutant genes may cause the synthesis of a structurally altered enzyme protein whose stability is reduced, causing it to be more rapidly broken down in vivo (Harris, 1970).

Genetically determined protein variants have been found to differ by the substitution of amino acids in polypeptide chains (Ingram, 1961), by the association of fundamental units in varying combinations, as in the case of the lactate dehydrogenases (Markert, 1963) or, as in the case of certain alkaline phosphatase isoenzymes, in their content of neuraminic acid (Robinson and Pierce, 1964); the latter explanation has been shown to be inapplicable in the case of the variation between the isoenzymes of normal and neoplastic pancreas.

Alkaline phosphatase is secreted into the pancreatic juice of the dog (Nothmann, 1944) and man (Warnes, Hine, and Kay, 1969), and ligation of the pancreatic ducts in the dog results in a progressive rise in the serum alkaline phosphatase of pancreatic origin (Nothmann, 1944). Nothmann further suggested that the level of serum alkaline phosphatase might be used as a diagnostic aid in pancreatic diseases, especially in those producing duct occlusion. The serum from our patient with the carcinoma of the pancreas contained an elevated alkaline phosphatase level which was mainly of 'liver' origin; unfortunately, serum from the patient with the insulinoma was not available for study. Though in many cases an elevated serum alkaline phosphatase level in patients with tumours of the pancreas is due either to liver metastases or to obstruction of the common bile duct, there is recent evidence that pancreatic tumours may themselves be the source of elevated levels of alkaline phosphatase in serum (Mann, Rayner, and Gourevitch, 1969; Gjone, Fretheim, Nordöy, Jacobsen, and Elgjo, 1970). Knowledge of the isoenzyme characteristics of normal pancreatic alkaline phosphatase and the tumour variant should permit early recognition of this tumour isoenzyme in serum and duodenal juice.

We thank Dr H. T. Howat for his help and encouragement. We are most grateful to $\mathrm{Dr} H$. T.
Howat, Dr R. Holmes, and Mr H. B. Torrance for permission to study their patients; to Mrs D. Riley for expert secretarial assistance, and to the Department of Medical Illustration, Manchester Royal Infirmary, for preparation of the diagrams and photographs.

\section{References}

Bachhawat, B. K. (1969). Some considerations on alkaline phosphatase. Ann. N.Y. Acad. Sci., 166, 696-698.

Bahr, M., and Wilkinson, J. H. (1967). Urea as a selective inhibitor of human tissue alkaline phosphatases. Clin. chim. Acta, 17, $367-370$.

Burstone, M. S. (1958a). Histochemical comparison of Naphthol AS-phosphates for the demonstration of phosphatases. $J$. nat. Cancer Inst., 20, 601-615.

Burstone, M. S. (1958b). The relationship between fixation and techniques for the histochemical localization of hydrolytic enzymes. J. Histochem. Cytochem., 6, 322-339.

Butterworth, P. J., and Moss, D. W. (1966). Action of neuraminidase on human kidney alkaline phosphatase. Nature (Lond.), 209, 805-806.

Fishman, W. H. (1969). Immunologic and biochemical approaches to alkaline phosphatase isoenzyme analysis: the Regan isoenzyme. Ann. N.Y. Acad. Sci., 166, 745-759.

Fishman, W. H., Green, S., and Inglis, N. I. (1963). L-phenylalanine: an organ specific, stereo-specific inhibitor of human intestinal alkaline phosphatase. Nature (Lond.), 198, 685-686.

Fishman, W. H., Inglis, N. I., Stolbach, L. L., and Krant, M. J. (1968). A serum alkaline phosphatase isoenzyme of human neoplastic cell origin. Cancer Res., 28, 150-154.

Gault, M. H., Cohen, M. W., Kahana, L. M., Leelin, F. T., Meakins, J. F., and Aronovitch, M. (1967). Serum enzymes in patients with carcinoma of lung: lactic-acid dehydrogenase, phosphohexose isomerase, alkaline phosphatase and glutamic oxaloacetic transaminase. Canad. med. Ass. J., 96, 87-94.

Gjone, E., Fretheim, B., Nordöy, A., Jacobsen, C. D., and Elgjo, K. (1970). Intractable watery diarrhoea, hypokalaemia and achlorhydria associated with pancreatic tumour containing gastric secretory inhibitor. Scand. J. Gastroent., 5, 401-408.

Harris, H. (1970). Genetical theory and the 'inborn errors of metabolism.' Brit. med. J., 1, 321-327.

Ingram, V. M. (1961). Hemoglobulin and its Abnormalities. Thomas, Springfield, Illinois.

Kaplan, M. M., and Rogers, L. (1969). Separation of human serumalkaline-phosphatase isoenzymes by polyacrylamide gel electrophoresis. Lancet, 2, 1029-1031.

Kind, P. R. N., and King, E. J. (1954). Estimation of plasma phosphatase by determination of hydrolysed phenol with aminoantipyrine. J. clin. Path., 7, 322-326.

Klein, U. E. (1968). Alkaline phosphatase in liver cirrhosis and rectal cancer. Lancet, 2, 1396.

Lancet (1969). Annotation. Ectopic alkaline-phosphatase production by tumours. Lancet, 2, 1236-1237.

Mann, J. R., Rayner, P. H. W., and Gourevitch, A. (1969). Insulinoma in childhood. Arch. Dis. Childh., 44, 435-442.

Markert, C. L. (1963). Lactate dehydrogenase isoenzymes: dissociation and recombination of subunits. Science, 140, 1329-1330.

Morton, R. K. (1954). The purification of alkaline phosphatases of animal tissues. Biochem. J., 57, 595-603.

Newton, M. A. (1967). The clinical application of alkaline phosphatase electrophoresis. Quart. J. Med., 36, 17-28.

Nichols, F., Bower, B., Williams, H., and Martin, R. (1966). In Proceedings of the 48th Annual Meeting of the Endocrine Society, Chicago, June, 1966, p. 107.

Nothmann, M. M. (1944). Effect of ligation of pancreatic ducts on the serum phosphatase. Proc. Soc. Exp. Biol. (N.Y.), 57, .

Posen, S., Neale, F. C., and Clubb, J. S. (1965). Heat inactivation in the study of human alkaline phosphatases. Ann. intern. Med., 62, 1234-1243.

Robinson, J. C., and Pierce, J. E. (1964). Differential action of neuraminidase on human serum alkaline phosphatases. Nature (Lond.), 204, 472-473.

Smith, I., Lightstone, P. J., and Perry, J. D. (1968). Separation of human tissue alkaline phosphatases by electrophoresis on acrylamide disc gels. Clin. chim. Acta, 19, 499-505. 
Stolbach, L. L. (1969). Clinical application of alkaline phosphatase isoenzyme analysis. Ann. N.Y. Acad. Sci., 166, 760-773.

Stolbach, L. L., Krant, M. J., and Fishman, W. H. (1969). Ectopic production of an alkaline phosphatase isoenzyme in patients with cancer. New Engl. J. Med., 281, 757-762.

Timperley, W. R. (1968). Alkaline-phosphatase-secreting tumour of lung. Lancet, 2, 356.

Timperley, W. R., and Warnes, T. W. (1970). Alkaline phosphatase in meningiomas. Cancer (Philad.), 26, 100-103.
Warnes, T. W., and Bulmer, D. (1970). Histochemical studies on pancreatic alkaline phosphatase. J. Anat., 106, 410.

Warnes, T. W., Hine, P., and Kay, G. (1969). Alkaline phosphatase in duodenal juice following secretin and pancreozymin. (Abstr.) Gut, 10, 1049.

Warnock, M. L., and Reisman, R. (1969). Variant alkaline phosphatase in human hepatocellular cancers. Clin. chim. Acta, 24, 5-11. 